\title{
Variability reduction through optimal combination of wind/wave resources - An Irish case study
}

\author{
Francesco Fusco $^{\mathrm{a}, *}$, Gary Nolan ${ }^{\mathrm{b}}$, John V. Ringwood ${ }^{\mathrm{a}}$ \\ ${ }^{a}$ Department of Electronic Engineering, National University of Ireland Maynooth, Maynooth, Co. Kildare, Ireland \\ ${ }^{\mathrm{b}}$ EirGrid plc, Transmission System Operator, The Oval, 160 Shelbourne Road, Ballsbridge, Dublin 4, Ireland
}

\section{A R T I C L E I N F O}

\section{Article history:}

Received 8 July 2009

Received in revised form

22 September 2009

Accepted 22 September 2009

Available online 12 October 2009

\section{Keywords:}

Wave energy

Wind energy

Combination of renewable energies

Power output variability

Ireland

\begin{abstract}
A B S T R A C T
This study presents a methodology to assess the possible benefits of the combination of wind energy with the still unexploited, but quite significant in Ireland, wave energy. An analysis of the raw wind and wave resource at certain locations around the coasts of Ireland shows how they are very low correlated on the South and West Coast, where the waves are dominated by the presence of high energy swells generated by remote westerly wind systems. As a consequence, the integration of wind and waves in combined farms, at these locations, allows the achievement of a more reliable, less variable and more predictable electrical power production. The resulting benefits are particularly clear in the case of a relatively small and quite isolated electrical system such as the Irish one. Here, in fact, high levels of wind penetration strongly increase the requirement of surplus capacity and cause a much lower efficiency for conventional thermal plants.
\end{abstract}

(c) 2009 Elsevier Ltd. All rights reserved.

\section{Introduction}

In response to the relatively urgent need to reduce the dependence from fossil fuels, particularly in the sectors of energy supply, industry and transport, many legislative organs worldwide have set some targets to constrain the turning towards renewables. In particular, the European Union stated that a 20\% target for the overall share of energy from renewable sources and a 10\% target for energy from renewable sources in transport would be appropriate and achievable objectives, and that a framework that includes mandatory targets should provide the business community with the long-term stability it needs to make rational, sustainable investments in the renewable energy sector which are capable of reducing dependence on imported fossil fuels and boosting the use of new energy technologies [1]. Along with these mandatory targets for the EU member countries, many of the nations set their own targets locally. In the specific case of Ireland, on which this study is focused on, the target to be achieved in 2010 from the EU Directive is $13.2 \%$ of gross electricity consumption from renewable sources, but nationally Ireland set a more ambitious target of $15 \%$ by 2010 and 33\% by 2020 .

\footnotetext{
* Corresponding author. Tel.: +353 851107337; fax: +353 17086027.

E-mail address: francesco.fusco@eeng.nuim.ie (F. Fusco).
}

In the most recent study from the independent electricity transmission system operator in Ireland, Eirgrid, it was reported that the installed conventional generation capacity is 6013 MW and that the installed renewable capacity is greater than $1300 \mathrm{MW}$, mainly deriving from wind (1050 MW) and hydro (nearly $240 \mathrm{MW}$ ). The demand for electrical energy, showing a peak of $4906 \mathrm{MW}$ in 2007 , is growing at a rate of approximately $3 \%$ per annum for midyear data, and at an estimated rate in the range of $2-4 \%$ per annum for the peak demand (although a revision of these figures between 2008 and 2010 is expected due to the slowing down of the economy). In order to realise the 2020 target of $33 \%$ of electricity demand to be met by renewables, Ireland is putting particular reliance on wind, so that connection of $250 \mathrm{MW}$ wind capacity has already been scheduled and there is a plan to assign further $3900 \mathrm{MW}$ in the next two and a half years [2].

Such a high level of wind penetration, however, does not come without difficulties, as was reported in Ref. [3]. It requires higher surplus capacity for supply security reasons (reliability impact), due to the source variability and difficulty of prediction, and it causes a much lower capacity factor for conventional plants (balancing impact). More frequent on/off and output variations for thermal plants significantly affects their efficiency with resulting higher electricity production costs and $\mathrm{CO}_{2}$ emissions. So, for example, considering a system with peak demand of $5000 \mathrm{MW}$, while the expected $\mathrm{CO}_{2}$ emission savings would be nearly $5.4 \%$ for an installed wind capacity of $500 \mathrm{MW}$, an increase to $1500 \mathrm{MW}$ would cause the 
emission savings to raise only up to $12.9 \%$ (and not up to an expectable 16.2\%) [3]. The capacity credit, measuring the amount of load that can be provided by a variable plant with no change in the reliability of supply (and so effectively the actual amount of conventional plants that can be displaced by variable renewable plants) is heavily affected as well. An Irish study from Eirgrid, based on 2006 wind data, established that this capacity credit is reasonably significant at low levels of wind penetration, but the benefit tends towards saturation as wind penetration levels increase, as illustrated in Fig. 1. This is because there is a significant risk that a single source of failure (i.e. very low or very high wind speeds across the country) will result in all wind farms producing practically no output for a number of hours, even allowing for geographic diversity [4].

These effects are particularly stark in the specific case of Ireland, which has little scope to smooth out the intermittent production pattern of wind through interconnection on scale. Consider, in fact, that the power system in the Republic of Ireland and Northern Ireland acts as a single power system of about $8500 \mathrm{MW}$, considerably smaller than the United Kingdom's (76,000 MW) and not comparable at all to the continental Europe UCTE power system $(600,000 \mathrm{MW})$. Note that the interconnector between Northern Ireland and Scotland, and the planned interconnections between Ireland and UK and France are non-synchronous DC connections and do not contribute to create a single system. The wind penetration over the global power system, therefore, will be significantly higher than in other countries, making the cited difficulties of reliability impact, balancing impact and saturation of the capacity credit particularly significant in the attempt to achieve the stated $33 \%$ target. This issue of the integration of a high share of intermittent resources into the energy system, especially the electricity supply, is considered as one of the main challenges of renewable energies for sustainable development $[5,6]$.

The main reason why the value of wind energy declines (indeed this is true for any renewable source) lies in the fact that the output from successive increments of capacity is correlated with that already in the system [7]. In contrast, combining capacity from renewables with uncorrelated or complementary outputs can be of considerable benefit, so that the potential synergies among different renewable sources are clearly much too important to ignore, as they may often make the combined exploitable potential larger than the sum of the parts considered in isolation [8]. A number of studies have been carried out on the large-scale integration of power from renewable into the electricity supply [9-11].
Ireland, together with the considerable wind potential, offers an enormous ocean wave resource, which is expected to make a significant contribution towards Ireland's future energy requirements (note that innovative combined wind and wave energy conversion systems are being developed [12]). Moreover, it offers the possibility of introducing that diversity in the renewable sources mix that may help to reduce the variability and uncertainty in the produced power, so to improve its reliability, at high level of intermittent source penetration in the power system. This study will assess that the correlation between the wind and wave resource can be quite low over significant parts of the year, particularly at some locations, so that their aggregation and combination can reduce the overall variability of the power produced, with all the resulting benefits in terms of improved capacity credit and improved effectiveness in the reduction of green house emissions.

Unfortunately wave energy is still far from being a developed and well tested technology, so that it is not expected to make a significant contribution to a more renewable-oriented power supply system before the year 2020. The results of this study, however, will hopefully make a significant contribution to eventual attempts to the achievement of further targets that may be set in the following decades, consisting of much higher levels of penetration of renewable sources in the power system.

\section{Methodology}

The key benefit, deriving from the diversification of the mix of renewable technologies, lies in the possibility of reducing the variability of the produced power. When adopting a single variable source (for example wind) the only way to reduce variability is by geographical diversity and displacement of the farms. When considering different variable sources, if they are uncorrelated, their combination is a powerful alternative in order to obtain a reduction of the overall variability of the produced power.

The methodology will therefore focus, firstly, on the assessment of the correlation between raw wave and wind power, as discussed in Section 2.2, available at different significant off-shore locations around Ireland, which are documented in Section 2.1. The variability and the predictability of the power produced by hypothetical wind and wave farms are then quantified according to the methodology described in Section 2.3. Finally, Section 2.4 presents the error analysis of the adopted methodology for this study.

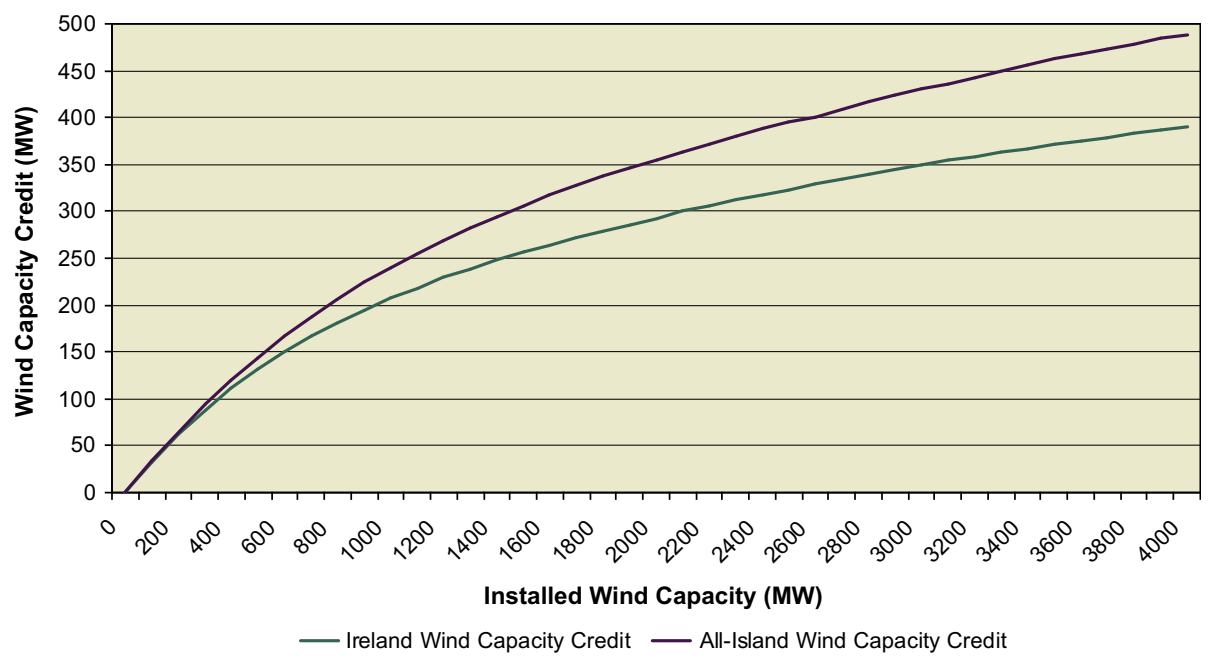

Fig. 1. Wind capacity credit in Ireland, with respect to installed wind capacity [2]. 


\subsection{Available data and locations}

The data utilised for this study was provided by the Irish Marine Institute in the form of hourly spaced observations collected around the coast of Ireland by means of weather data buoys. The 4 buoys which will be considered are located as in Fig. 2, with some other locations neglected due to the lack of a complete set of observations, because of long periods of operational problems. These sites represent, however, a significant enough set in order to cover the main diversities in the Irish wind-wave climates.

The observations consist of wind speed $v_{\mathrm{w}}$, wave period $T_{\mathrm{z}}$ and significant wave height $H_{\mathrm{s}}$ time series collected in the period from January 2002 to January 2005. Due to technical problems experienced by the different data buoys, the time series are affected by several sets of missing measurements (single points to entire days). A preprocessing procedure was then implemented in order to reconstruct some of them. Up to 2 missing samples were interpolated through cubic splines [13], while more than 2 samples-long holes were discarded. This still allowed the availability of significant portions of the observations (minimum 168 samples-long, corresponding to 3 weeks) for at least two months of every season in each year considered.

\subsection{Raw data analysis methodology}

The variability of the power produced from a mixed farm is only reduced if the different variable sources appear in different moments so that they balance each other's variations. This property can be quantified through the cross-correlation, given by the following expression, for two generic signals, $x(k)$ and $y(k)$ :

$c(\tau)=\frac{1}{N} \sum_{k=1}^{N-\tau} \frac{\left[x(k)-\mu_{k}\right]\left[y(k+\tau)-\mu_{k}\right]}{\sigma_{x} \sigma_{y}}$

where $\mu_{x}, \mu_{y}$ and $\sigma_{x}, \sigma_{y}$ are the mean and the standard deviation of $x$ and $y$. The quantity $c(\tau)$ gives the correspondence between two signals, at a time lag $\tau$. In our study, we are particularly interested in

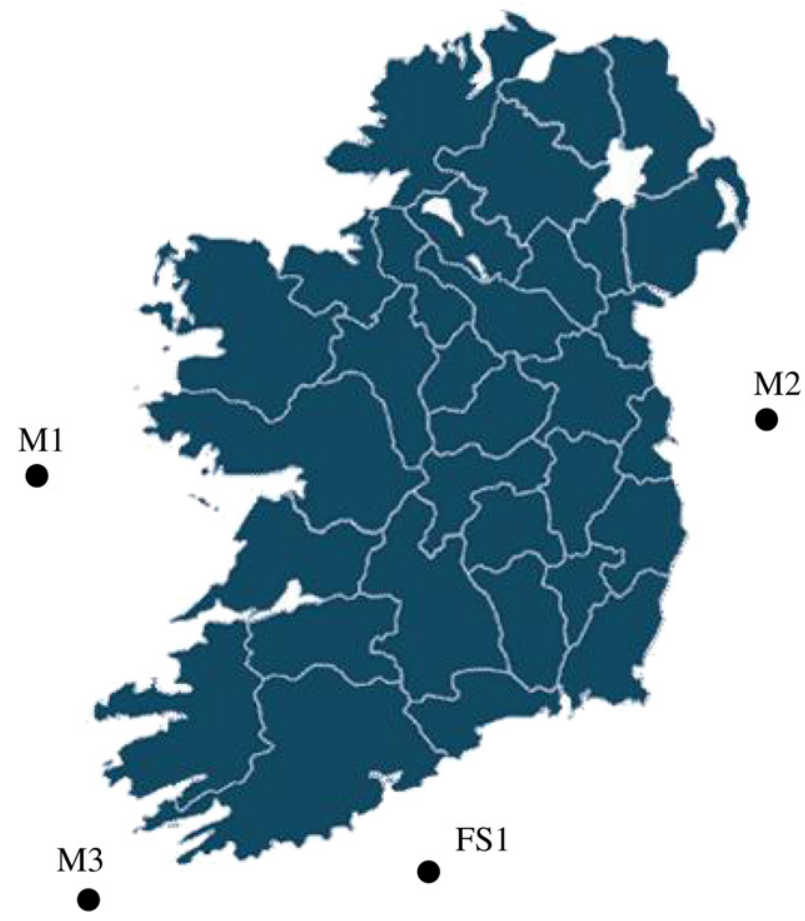

Fig. 2. Locations of the Irish Marine Institute data buoys. assessing the instantaneous correspondence between wind and wave power at the different locations, so $c(0)$ is of particular interest, with the following interpretation:

- $c(0)=1$ : The resources correspond perfectly, they are present at the same moments.

- $c(0)=0$ The resources have absolutely no correspondence, there is no common pattern in their evolution.

- $c(0)=-1$ : The resources have a perfect inverse correspondence, they are at the opposite of their mean level in every instant.

In order to obtain the available raw power, the time series of $v_{\mathrm{w}}$, $T_{\mathrm{Z}}$ and $H_{\mathrm{S}}$ must be converted into units of power. In this respect, the wind power density (power per unit area) is calculated by means of the following expression [8]:

$P_{\text {wind }}=\frac{1}{2} \rho_{\mathrm{a}} v_{\mathrm{w}}^{3}\left[\frac{W}{m^{2}}\right]$

where $\rho_{\mathrm{a}}$ is the air density and $v_{\mathrm{w}}$ the wind speed. The wave power density (power per unit of crest width) is based on the following formula, valid for harmonic waves under the deep water assumption (water depth much greater then wave length), which is true at the considered off-shore locations [14]:

$$
P_{\text {wave }}=\frac{\rho_{\mathrm{w}} g^{2} H^{2} T}{32 \pi}\left[\frac{W}{m}\right]
$$
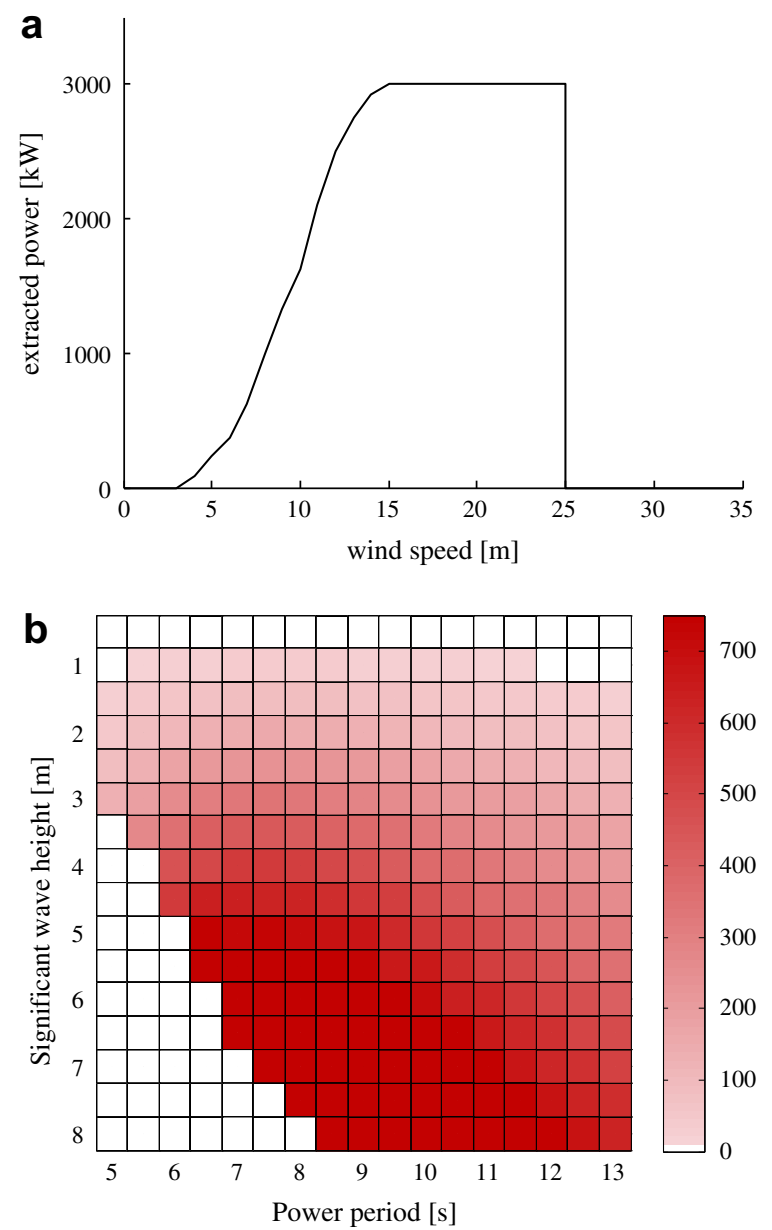

Fig. 3. (a) Power curve for a Vestas V90 3.5 MW wind turbine. (b) Power matrix for the Pelamis $750 \mathrm{~kW}$ wave energy converter. 
where $\rho_{\mathrm{w}}$ is the water density, $g$ is the gravity acceleration, $H$ is the wave height and $T$ is the wave period.

Correlation is a purely statistical measure and it is therefore important to provide some physical justification in order to support whatever conclusion might emerge from the analysis. A methodology will then be proposed, based on the knowledge about the process of wave generation from wind. It was experimentally shown how a wind speed $U_{19.5}$, measured at $19.5 \mathrm{~m}$ above the sea level, produces, if blowing over a sufficient fetch and for enough time, a wave system defined by the following significant wave height $H_{\mathrm{S}}$ and period $T_{\mathrm{z}}[15]$ :

$H_{\mathrm{s}} \approx 0.21 \frac{U_{19.5}^{2}}{g}$

$T_{\mathrm{z}}=\frac{2 \pi}{0.4} \sqrt{\frac{H_{\mathrm{s}}}{g}}$

This allows the calculation of the expected wave height and period, based on the wind speed measurements, and the comparison with the values actually observed. A significant disagreement would encourage the hypothesis of a low correlation between wind and wave power, probably due to the presence of a remotely generated wave system (generally a low frequency swell), which would be very likely to be observed off the West and South-West coast of Ireland, particularly exposed to the Atlantic Ocean.

\subsection{Power extracted from hypothetical mixed farms}

Initially, the available raw power must be converted into actual extracted power from hypothetical wind and wave farms. Regarding the power extracted from wind, the relatively mature state of wind turbine technology permits the use of well established power curves. A typical 3.5 MW off-shore wind turbine was chosen for this study, whose power curve is shown in Fig. 3a. Computing the extracted power from wave energy devices, on the other hand, is not as straightforward, mainly because of the fact that there is little established wave technology and the operating principles of the available devices are very diverse, so that it is difficult to find a standardised measure of the extracted power in the case of waves. For this study, the $750 \mathrm{MW}$ Pelamis wave energy converter is chosen, because of the well documented characteristics of its power production, which is articulated through the published power matrix, as in Fig. 3.b

In order to determine the power extracted from a farm, the power from single devices must be projected to the corresponding number of wind turbines and wave energy converters, depending on the considered mix. For this study $50 \mathrm{MW}$ farms have been considered, where the number of devices are calculated so that their combined yearly average power output level is $50 \mathrm{MW}$ and the considered mix is respected. The reason why the rated capacity is not used is that the capacity factors for wind turbines and the Pelamis are not the same, due to the significant differences in the probability distribution of their produced power, as it can be appreciated from Fig. 4. Wind turbines, most of the time, work either at low level or at full capacity, whereas the Pelamis power output is mostly concentrated at average levels, so that a comparison based solely on the capacity and not taking into account the capacity factor, would be quite unjust and might return misleading results.

A more precise estimation of a farm power output would involve the introduction of a smoothing effect due to the spatial diversity of the individual turbines/WECs, whereas only single point measurements are being utilised in this study. While the problem for wind
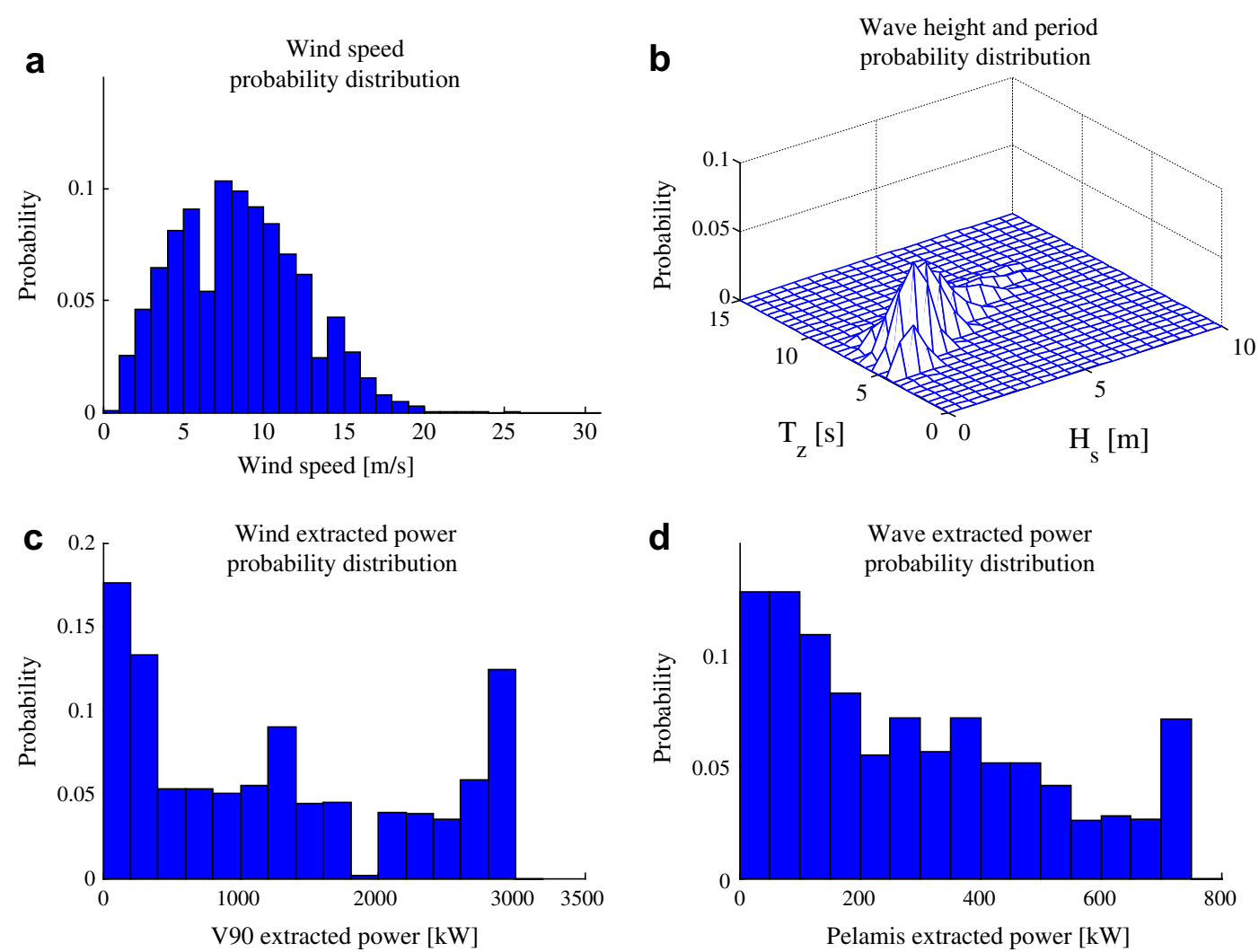

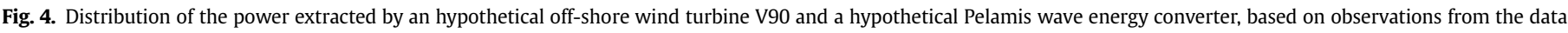
buoy $M_{1}$, West Coast of Ireland. 
farms has been well studied and some methodologies were developed (e.g. refer to $[16,17])$, the state of the art for wave energy is still too immature to allow such a methodology to be developed for wave energy converter arrays. This is the reason why this smoothing effect has been discarded in the present study.

Once the measurement time series from the data buoys at the different locations are converted in hypothetical power outputs from mixed wind and wave farms, their characteristics of variability and predictability are compared in order to evaluate the eventual benefits that a heterogeneous mix can introduce with respect to a single resource and the differences in characteristics with respect to the location.

The variability is analysed on the basis of three significant quantities.

1. An absolute variability index, $\Delta$, is calculated as the cumulative sum of the variations over all the considered data set:

$$
\Delta=\sum_{i=1}^{N-1}\left|x_{i+1}-x_{i}\right|
$$

where $x_{i}$ is the estimated power extracted at hour $i$.

2. The standard deviation $\sigma$ [18] is a useful measure, indicating a typical range, in $\mathrm{kW}$ or MW, around the average level for the produced power (e.g. with a 95\% probability the power output is within $\mathrm{a} \pm 2 \sigma$ range from the average level if the distribution is Gaussian).

3. The third variability measure proposed quantifies the number of hours (as a percentage over the total hours considered) the farms produce a certain power output level. This is particularly interesting, in that one of the main problems of wind farms is that they show considerable periods of time with zero power produced, so that it is very important to verify if the situation changes and to what extent when considering mixed farms.

Regarding the predictability, a very useful quantity is proposed, which is independent of any specific algorithm that may be used to produce the actual prediction, defined as the ratio of the variance of the optimal $k$-step-ahead prediction, to the variance of the real signal $\sigma_{x}^{2}$ :

$R^{2}(k)=\frac{\sigma_{\widehat{x} k}^{2}}{\sigma_{x}^{2}}$

This predictability index is bounded between 0 (signal completely unpredictable, white noise) and 1 (signal perfectly predictable, deterministic). An efficient algorithm for its computation was proposed in [19] and it is adopted for this study. Note that the quantity $R^{2}(k)$ is a simplification of a more general predictability notion based on mutual information theory [20], where only the linear interactions in the time series are considered. It is, however, enough for the comparison purposes of this study.

\subsection{Error analysis}

In order to properly evaluate and consider the results presented in this study, the basic hypothesis, assumptions and errors are here outlined.

The wind and wave measurements collected by the data buoys have an accuracy specified as follows:

- Hourly wind speed is with an accuracy of $\pm 2 \mathrm{kn}$, in the interval $[0,40] k n$, and of $\pm 5 \%$ in the interval $[40,200] k n$.
- The wave height is calculated as four times the root mean square (RMS) value of the wave elevation observed for $17.5 \mathrm{~min}$ every hour, and the accuracy is $\pm 2-5 \%$.

- The wave period is recorded on the basis of the number of times the wave elevation, observed for 17.5 min every hour, passes through the mean water level in upward direction. It is quantized so that the accuracy is $\pm 0.5 \mathrm{~s}$.

As explained in section 2.1, over the data collection period considered (January 2002 to January 2005), both long (several days) and short (a few samples) data segments are missing from the records. In order to extract large continuous portions of useful data a preprocessing procedure was applied were up to two consecutive missing samples were interpolated with cubic splines. For the presented results only contiguous segments at least 3 weeks long (168 samples) were considered.

The evaluation of the extracted power from the time series is based on certain assumptions over the particular device. In the case of wind, the well advanced state of the technology produced a certain convergence of the performance of the off-shore wind turbines available on the market, so that their power curves are quite comparable. The field of wave energy, on the other hand, is still an assortment of different devices, based on rather diversified operating principles, so that their power curves are very different among each other and can also be very site specific. The proposed device for this study is the Pelamis, because it is the one of the few devices which is well documented, as regard its power matrix characteristics, thanks to its relatively advanced state of testing and development. It is based on a robust concept designed for off-shore applications and high energy sea states, so that the results regarding wave energy are slightly West and South coast biased, in that the predominant sea states, in contrast to the East coast, occupy the central part of the Pelamis power matrix.

\section{Results}

According to the methodology outlined in Section 2, the results of this study are collected into a preliminary analysis of the raw wind and wave resource available at the considered off-shore locations, and then the evaluation of the possible benefits that heterogeneous farms can bring about in terms of reduced variability and improved predictability of the power injected into the grid.

\subsection{Wind and wave power around the coast of Ireland}

The instantaneous correlation coefficient $c(0)$ between wind and wave power, estimated on the basis of data collected through year 2002 to early 2005, is shown in Fig. 5 for the different locations and for different seasons. There is a clear difference between the East Coast, where the correlation between the wave and wind resource is quite strong, and the West and South coasts of Ireland, where wind and waves seem to be less correlated. This result was to be expected, as the West and South coasts of Ireland are completely exposed to the Atlantic Ocean and therefore to waves remotely generated by westerly wind systems, which have little correlation with the local weather conditions closer to the Irish coast and which are known to contain most of the wave energy (they are the so-called swells). The East Coast, on the other hand, due to the presence of Ireland itself as a shelter from the South-West prevailing swell waves, experiences mostly wind waves generated by local winds (either north esterlies or attenuated westerlies) so that the correlation is much higher.

The instantaneous correlation, however, gives only a limited view of a bigger picture, as it is clearer from the temporal 


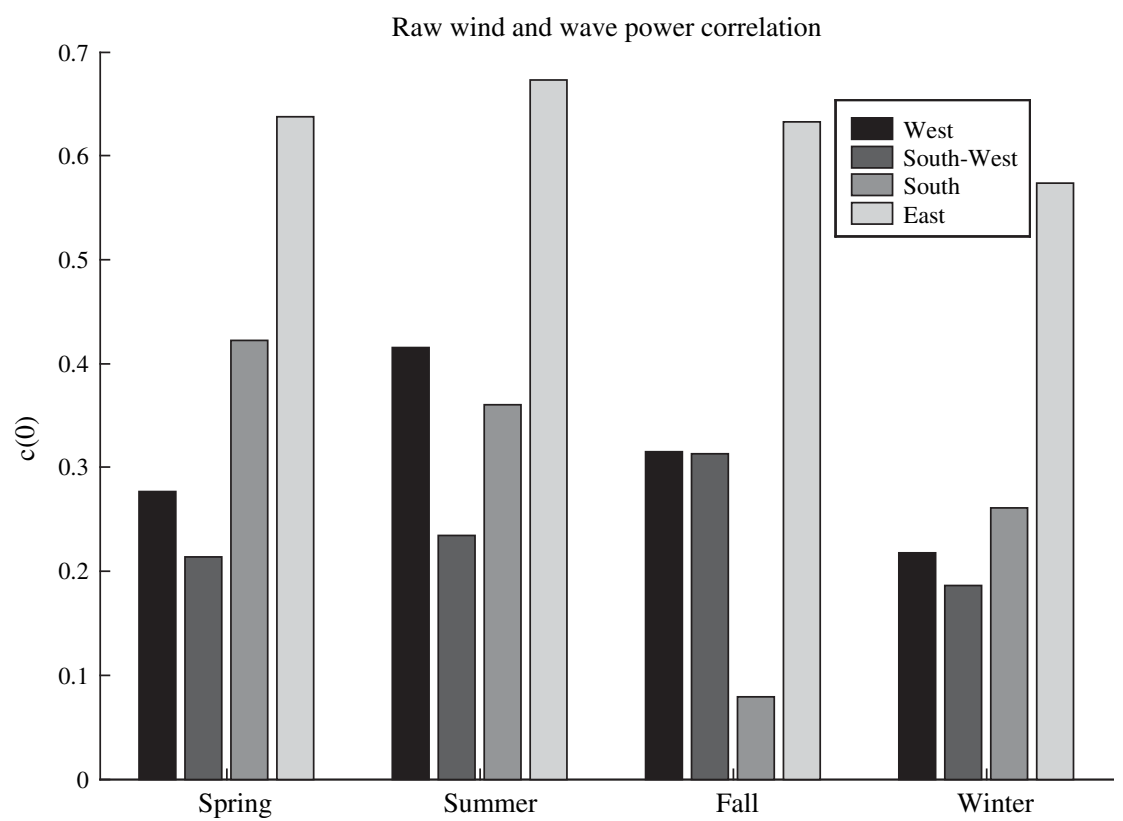

Fig. 5. Seasonal average of the instantaneous correlation, $c(0)$, between raw wind and wave power at different locations.

correlation details of Figs. 6 and 7, where the wind and wave power time series behavior is shown. The portion of data from the East Coast shows that wave and wind power, apart from a scaling factor, evolve according to the same dynamics and this confirms the hypothesis of the presence of mainly wind waves, generated by local winds. The slight delay, about $2-3 \mathrm{~h}$ (it can be determined as the maximum point of the temporal correlation), is due to the time required for the waves to develop, which is relatively short for low energies. Fig. 6, documenting the West Coast correlations, reveals a poor correspondence between waves and wind patterns, where there might be an independent swell superimposed on the local wind waves, which are evolving according to the local wind pattern.

A further confirmation that the low correlation at some locations is mainly due to the presence of a swell superimposed on local wind waves can be had by comparing the observed sea state with that expected due to the local wind conditions, according to the method outlined in Section 2.2. This comparison is expressed once again with the correlation and the results are plotted in Fig. 8, both for the wave period and the significant wave height. A much stronger agreement is found for the East Coast location, particularly regarding the wave period, whose estimation is quite uncorrelated
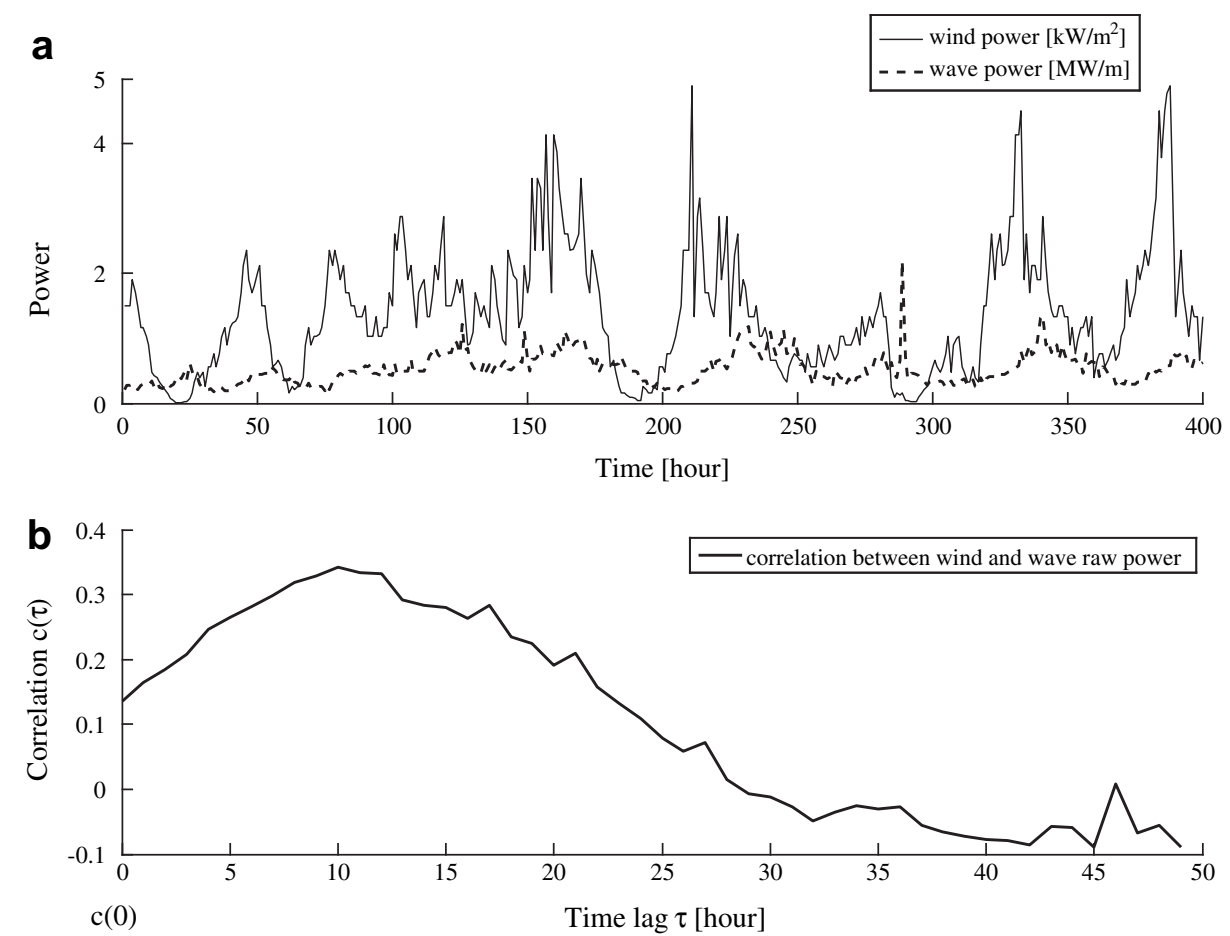

Fig. 6. Raw wind and wave power, with their estimated temporal correlation, for a sample collected in Winter 2004 from the $M_{1}$ data buoy, West Coast. 

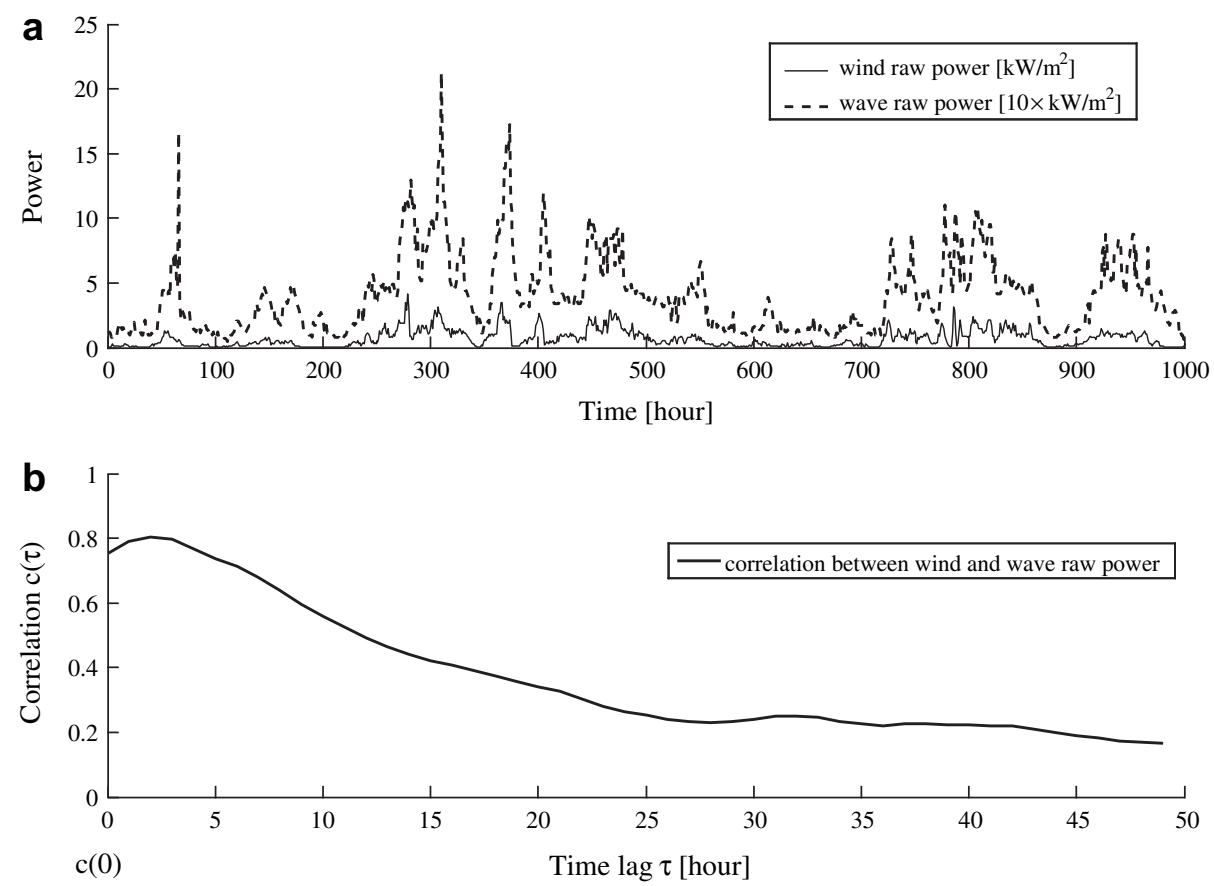

Fig. 7. Raw wind and wave power, with their estimated temporal correlation, for a sample collected in Summer 2004 from the $M_{2}$ data buoy, East Coast.

(or even slightly anti-correlated) with the real observations at the South and West locations. In order to have a clearer comprehension of the reasons for these results, Fig. 9 presents a detailed representation of the comparison of expected wave height and observed wave height at the West and East locations. While for the East Coast data, the agreement is quite good, the situation of the West Coast denotes an estimated wave height which is most of the time much lower than the observed one. The latter, in fact, contains waves that are not generated by local winds and that are completely neglected by this method. The same conclusion can be drawn from a detailed comparison of the estimated and observed wave periods, shown in Fig. 10. On the West Coast the expected wave period, most of the time, is much lower than the observed one, because the local wind conditions give rise to high frequency wind waves. The predominant sea state, however, is generally concentrated around the high period swells which are travelling from remote locations where
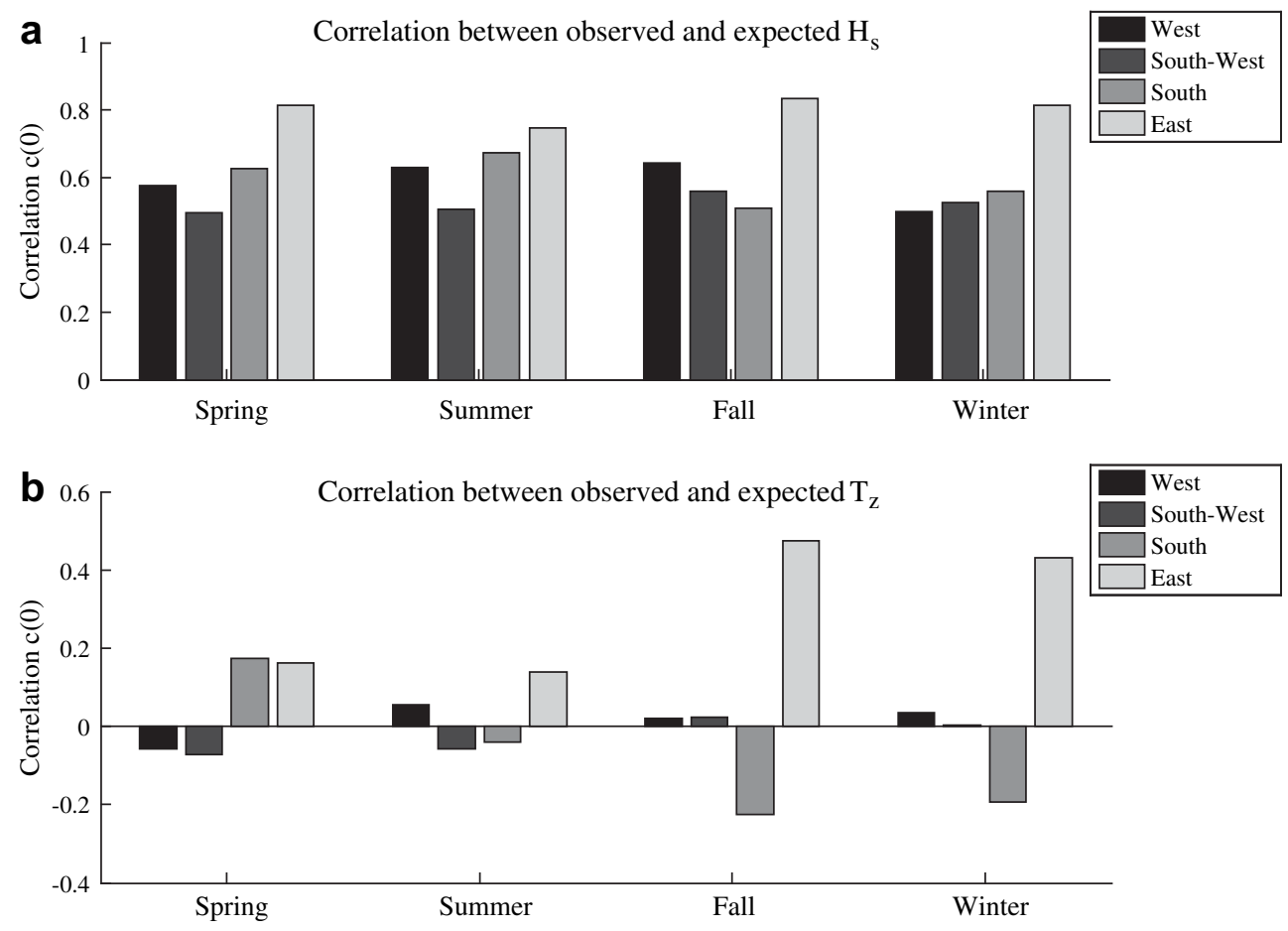

Fig. 8. Correlation between observed wave periods and significant wave heights, and their estimations based on the wind speed measurements. 
Location $\mathrm{M}_{1}$, West Coast, Summer 2003
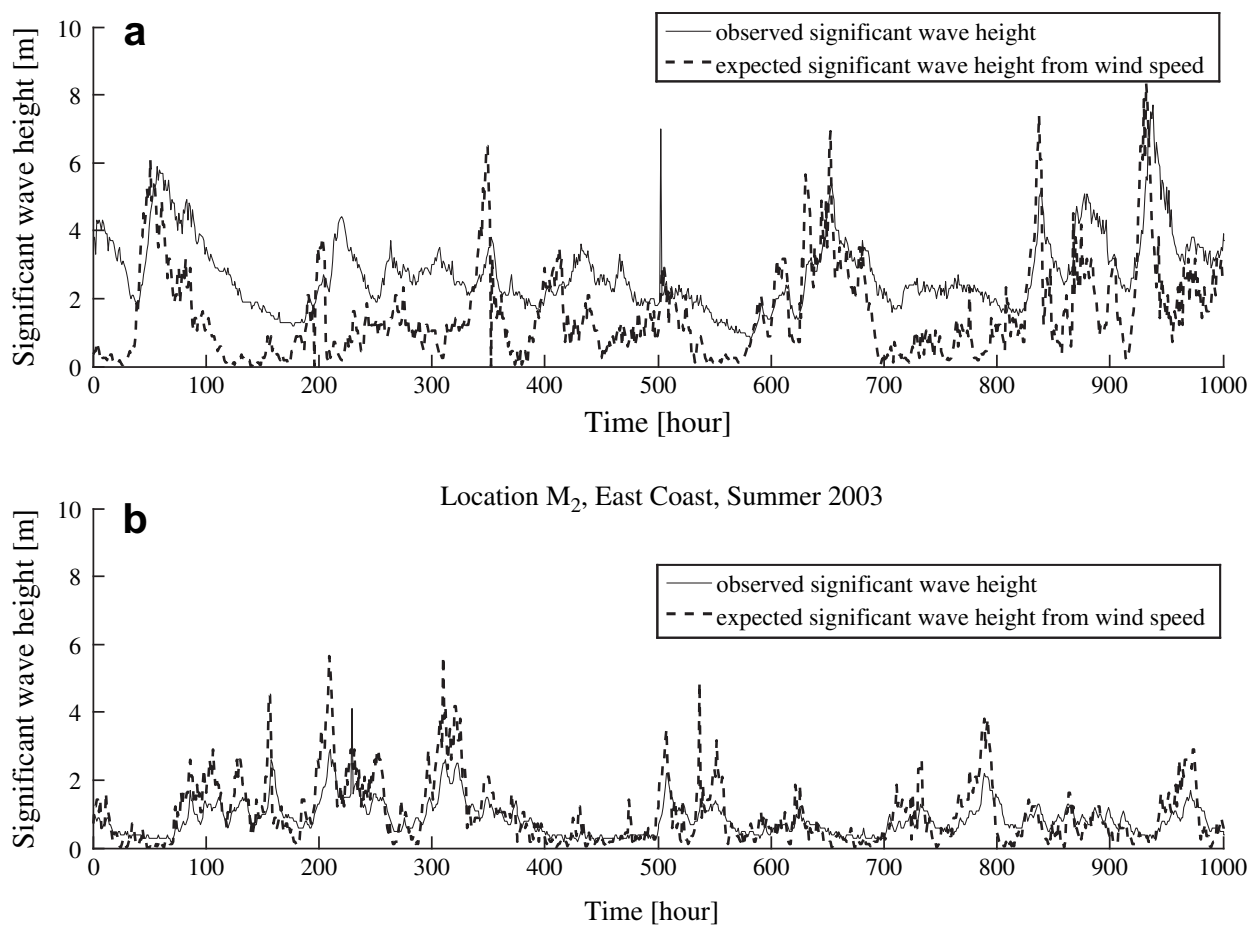

Fig. 9. A sample comparison between observed significant wave height and its estimation from wind speed measurements at the West and East Coast of Ireland.

they were developed. This situation would be very clear if wave spectra were available for the considered locations, but unfortunately they require higher sampling rates than those available from the meteorological data buoys utilised in this study.
In the view of this study's purposes, however, the results presented in Figs. 5-10 are more than enough to provide a clear picture of the global situation of the wind and wave energy resource around the West, South and East coasts of Ireland. In particular, the
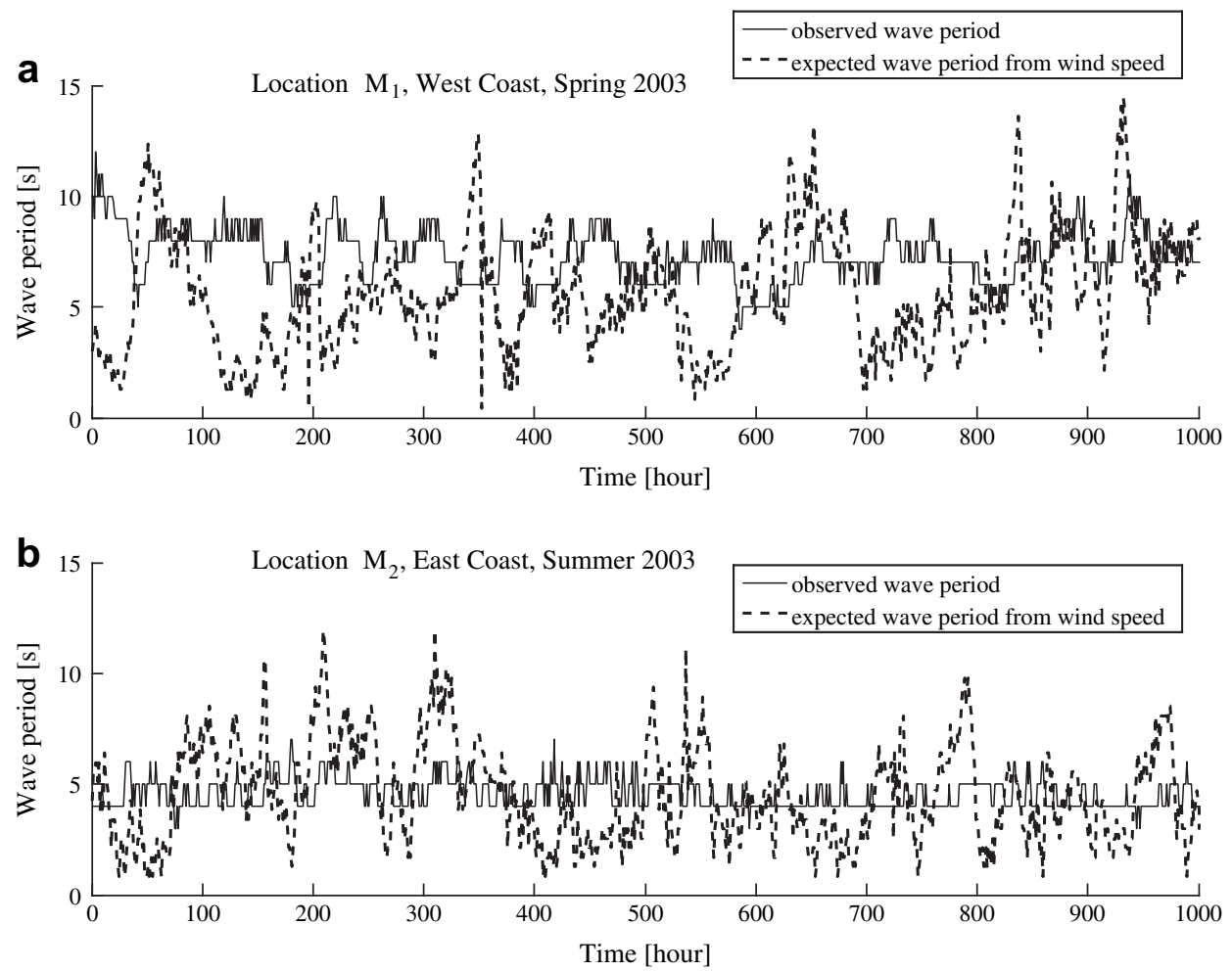

Fig. 10. A sample comparison between observed wave period and its estimation from wind speed measurements at the West and East Coast of Ireland. 

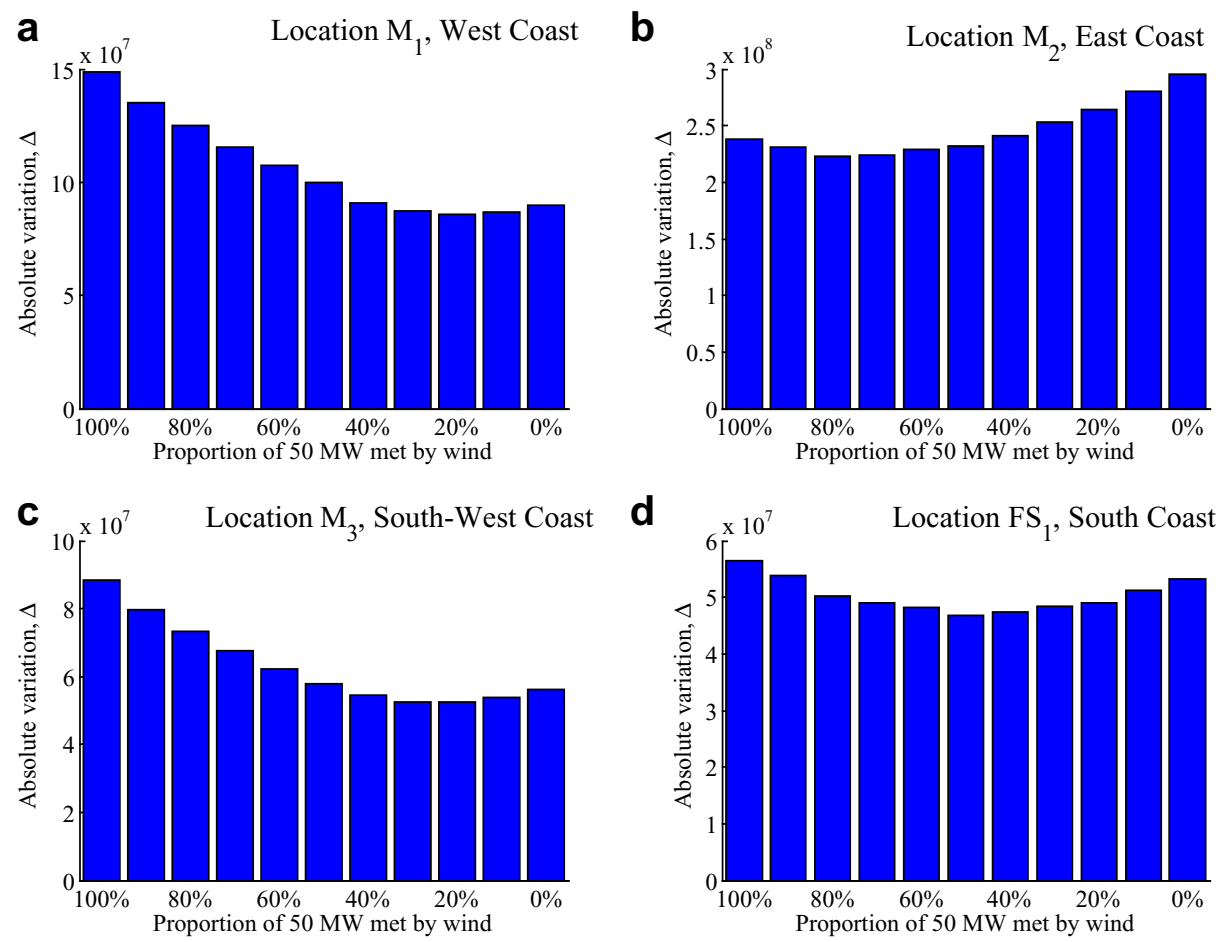

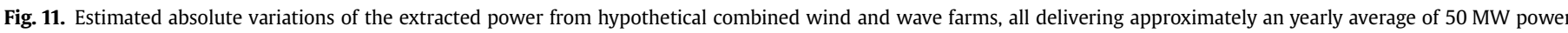
output, at different locations.

high energy swells, at the South and West locations, are independent from the local wind conditions, so that mixed wave and wind farms, at these locations, are a concrete opportunity to generate less variable and more consistent electrical power.
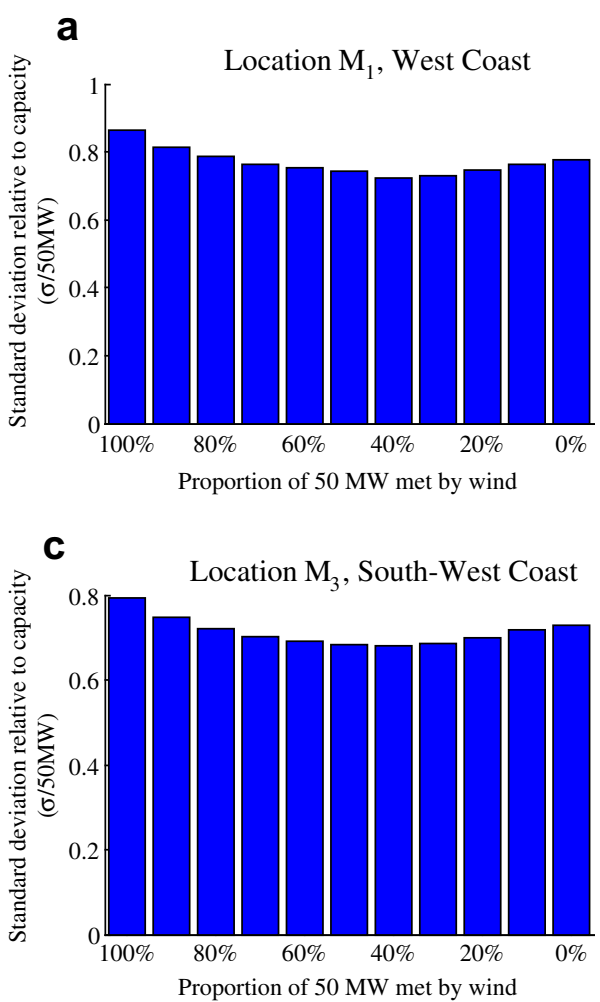

\subsection{Benefits of wind/wave combined farms}

The most obvious benefit that can be expected from a diversification of the renewable mix for the electricity production is the
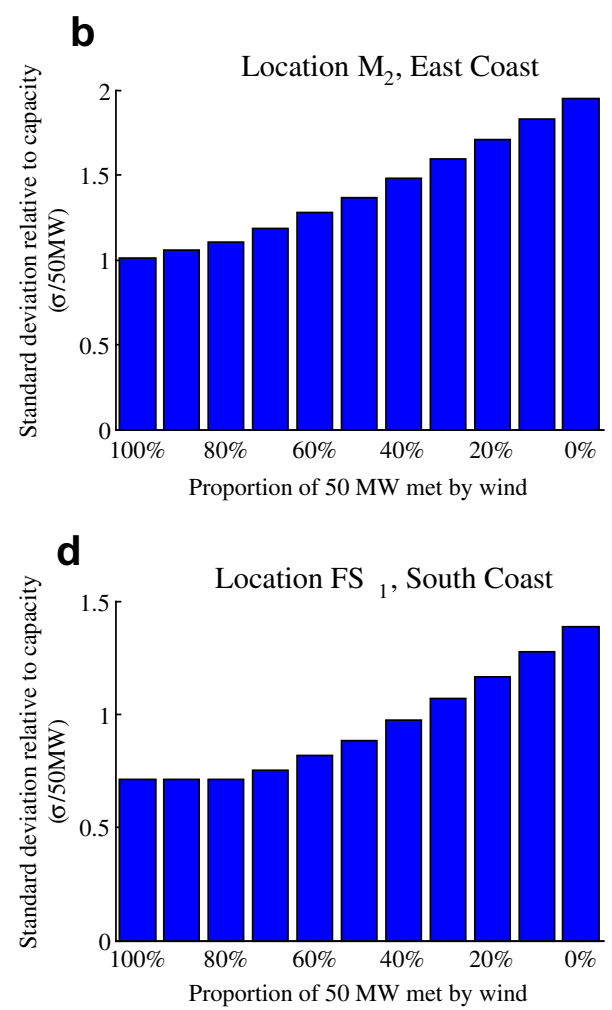

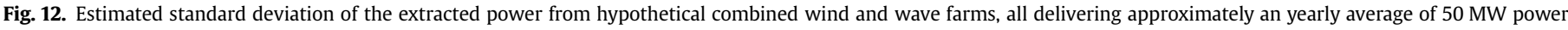
output, at different locations. 

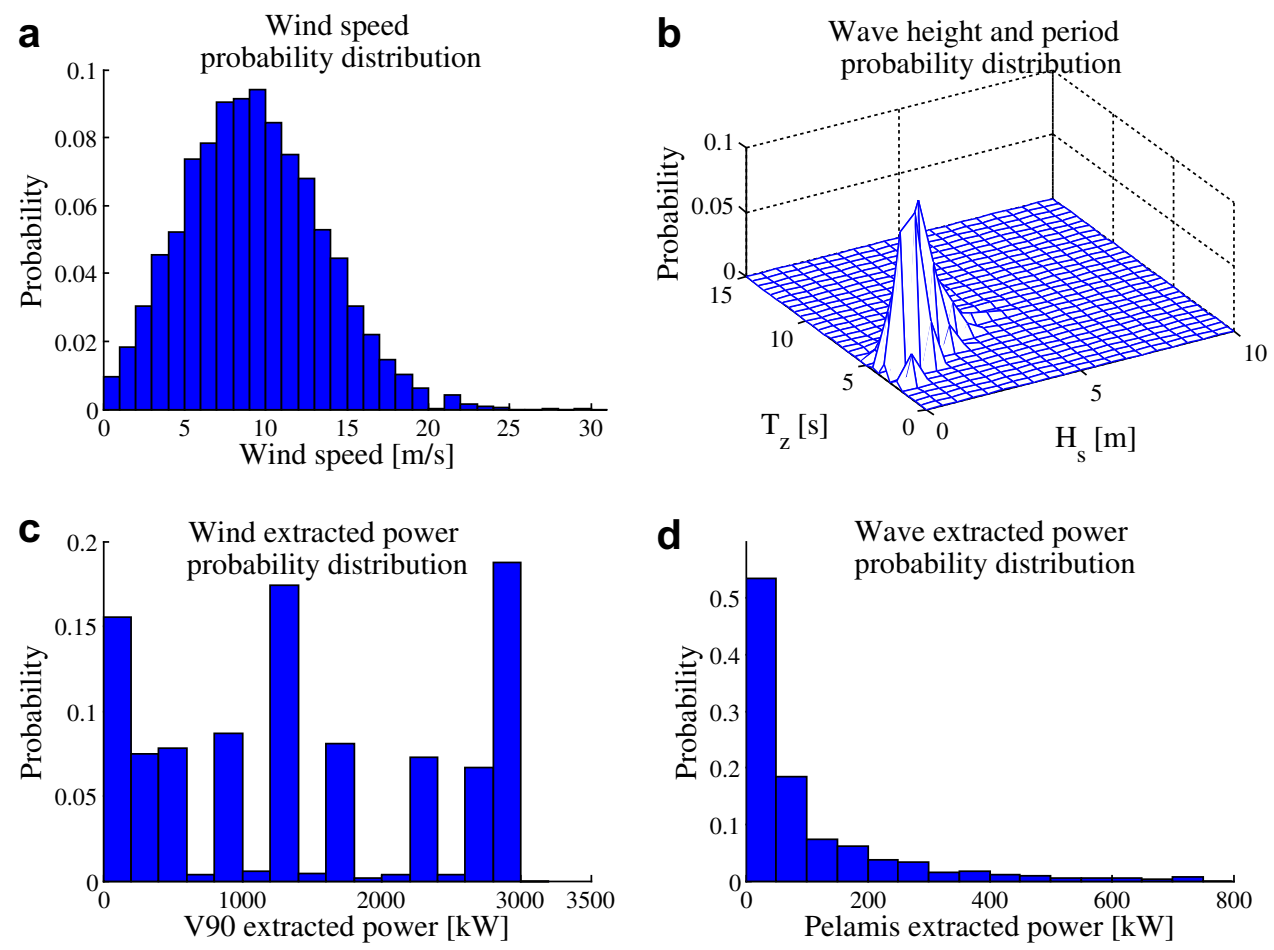

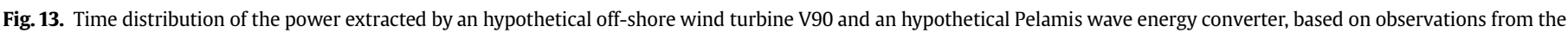
data buoy $F S_{1}$, South Coast of Ireland.

reduced variability, which directly reduces the required surplus capacity from traditional thermal plants and the frequency of their startups/shutdowns, thus improving the capacity credit deriving from the renewable farm.

Fig. 11 shows the absolute variation of power, at different locations, produced from farms composed of different mixes of wind energy and wave energy devices. The trend is quite clear for the West locations, where the variability reduces while moving to mostly wave-oriented solutions, and for the East coast, where the situation is reversed. A less clear trend can be observed for the South $F S_{1}$ location, where the best mix is somewhere inbetween.

A quite similar picture can be derived from the standard deviation analysis, which is shown in Fig. 12. Only for the South Coast
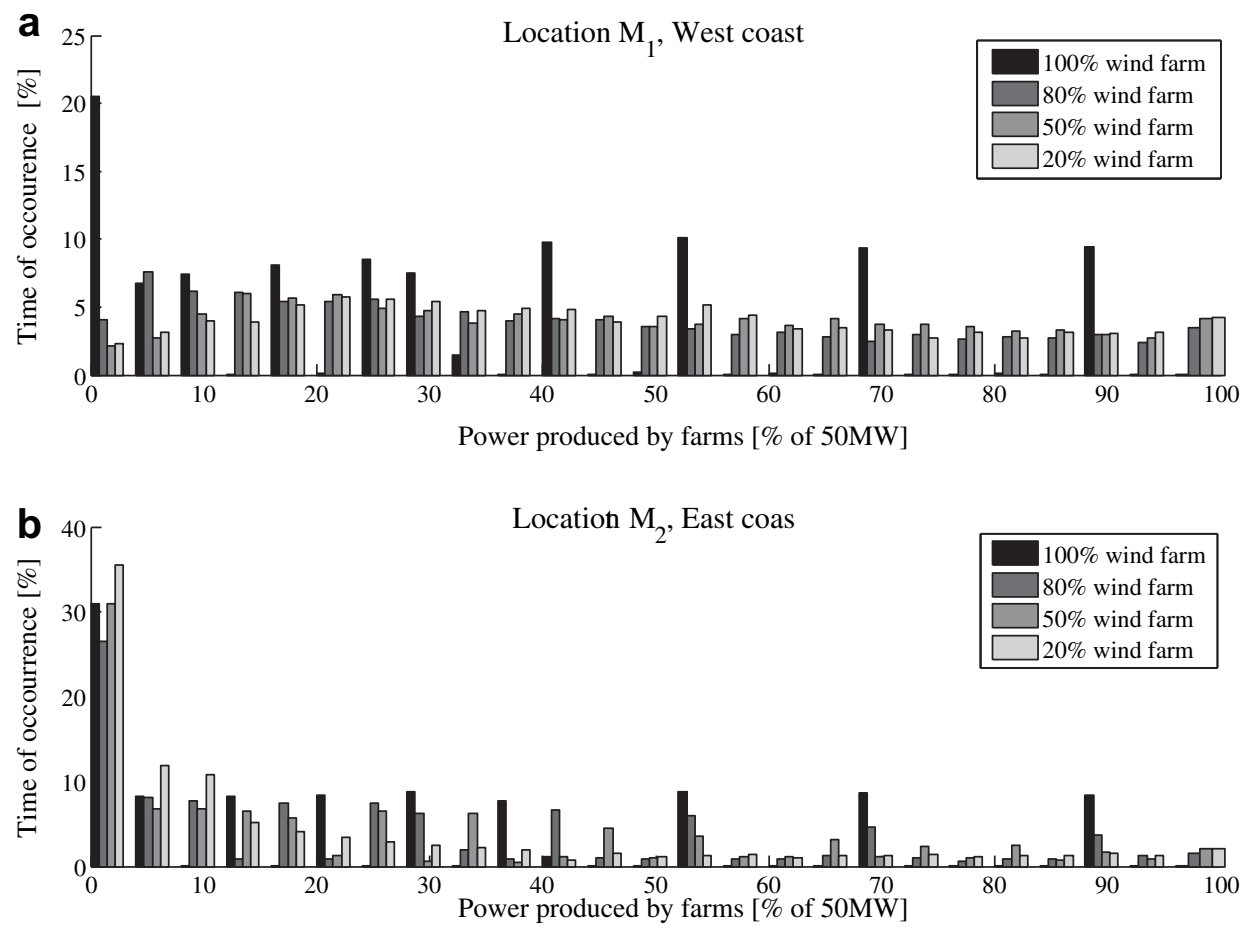

Fig. 14. Distribution of the power extracted by hypothetical combined wind and wave farms off the West and East Coast of Ireland. 

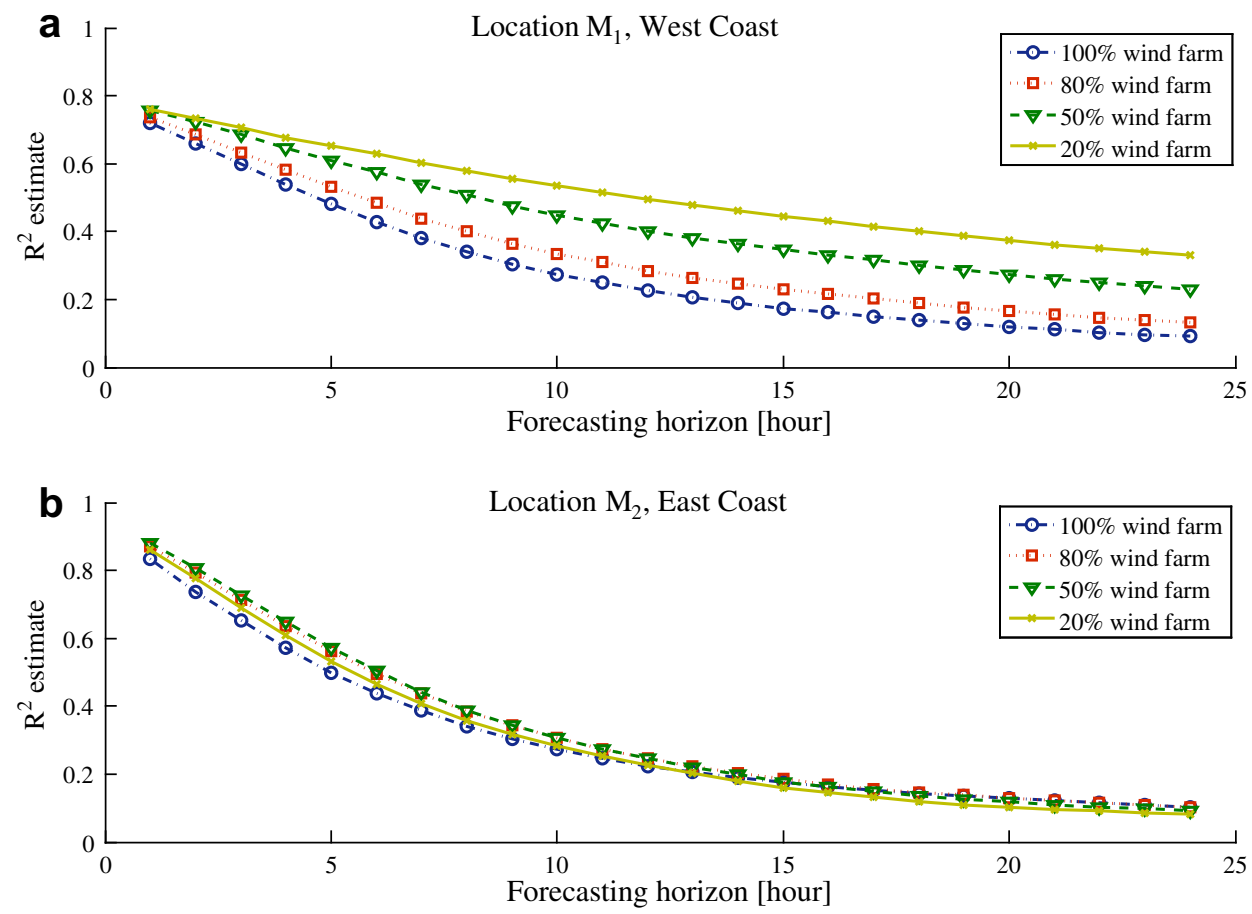

Fig. 15. Predictability of the power extracted from hypothetical combined wind and wave farms off the West and East Coast of Ireland.

location, the situation is different, in that it presents a better performance for mostly wind composed farms. This different situation for the two indices at the South location may be explained by the fact that, although there is a low correlation between the wind and wave resources, so that the global variability is reduced through combination, the wave energy devices would most of the time produce low power outputs (refer to Fig. 13), so that the extracted power excursion from the average level, measured by the standard deviation, would still be large.
One more important property to be considered is the time distribution of the power output from a farm, that is for how long a certain power output is experienced. Fig. 14 shows the two extreme situations of the West coast and East coast (South and South-West are somewhere in-between). Whereas the introduction of even a small percentage of wave energy, e.g. 20\%, in the mixed farms on the West Coast allows for a strong reduction of very low (or null) power production periods, the situation on the East Coast is not that appealing, as expected.
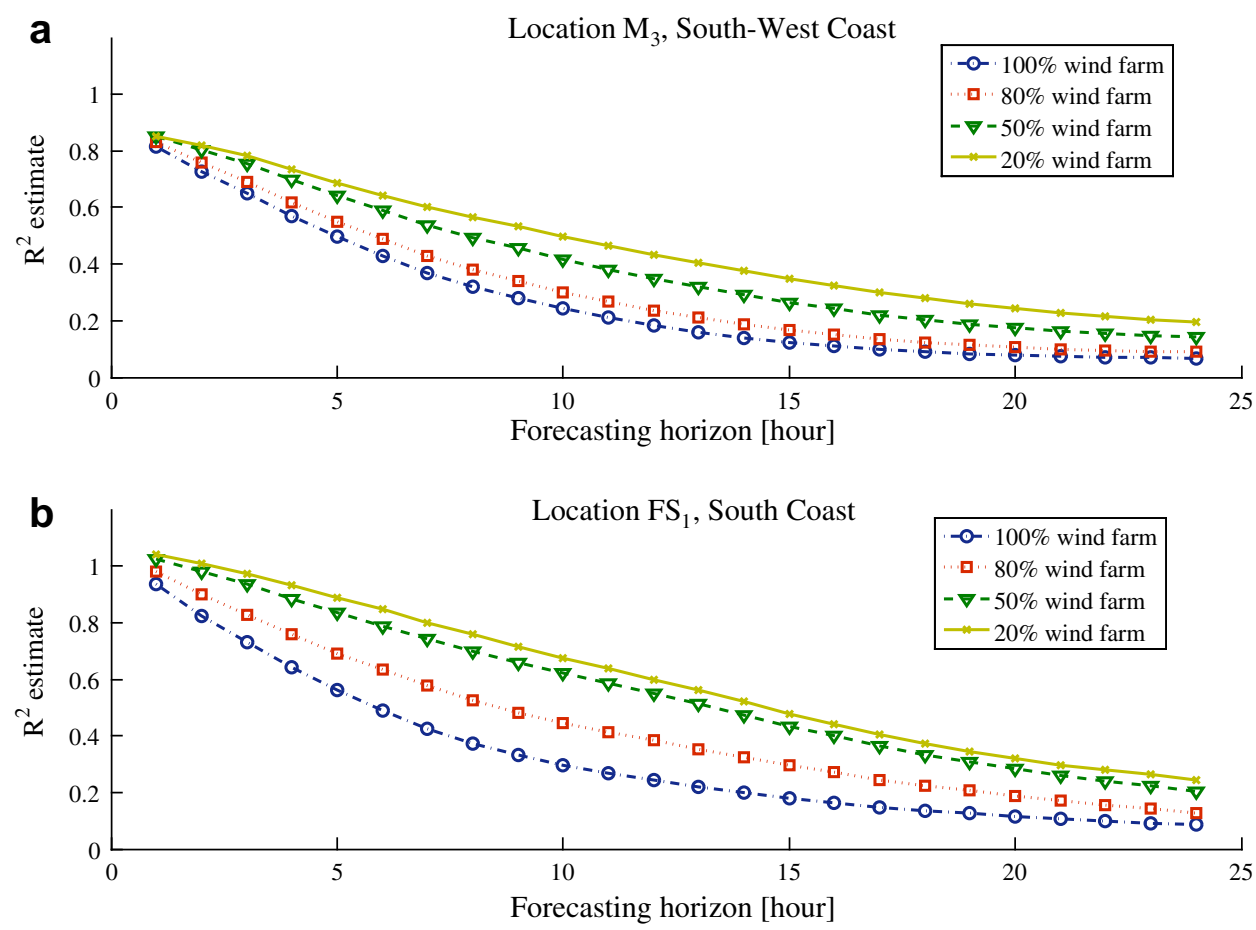

Fig. 16. Predictability of the power extracted from hypothetical combined wind and wave farms off the South-West and South Coast of Ireland. 
The final property considered in this study is the predictability of the power produced by combined wind and wave farms. Before presenting the results, it is worth noting that the power time series we are considering here have been statically mapped from wind speed and wave conditions time series, which means that their dynamics do not change. In reality, a filtering effect would be present, which would modify their dynamics, making the power time series smoother. Considering the wind, in particular, reasonable predictions of the wind power output from off-shore farms can be obtained for up to $48 \mathrm{~h}$ ahead (refer to $[21,22]$ ), but the actual wind speed is much harder to predict because of its rather erratic behavior. Waves, on the other hand, have much smoother dynamics, particularly the high energy swells, so that they are easier to predict. The smoothing effect introduced by wave farms cannot be reasonably estimated, as already said, so that for a more just comparison, the effect is discarded for the wind power as well. It emerges, therefore, from the results in Figs. 15 and 16, that there is an improvement when moving to more wave-oriented solutions on the West and South coasts, whereas no real change is experienced for the East location. Wind waves, predominant on the East are, in fact, more irregular than the big swells present off the South and West coast, so that their predictability is negatively affected.

\section{Conclusion}

The variability of the power produced from renewable sources and its uncontrollable nature negatively affects their effectiveness in reducing the requirement for thermal plants (it reduces their capacity credit) and makes them a less attractive and a potentially more expensive alternative.

Ireland, together with its great wind potential, also offers an important and enviable wave resource. This study is therefore focused on the assessment of the correlation between the two resources, at different locations around Ireland, and the possibility to reduce the variability of the power extraction if mixed wind and wave off-shore farms are adopted, with respect to the exploitation of solely one resource.

It is shown how the West and South coasts experience, most of the time, wave systems where the predominant (from an energy point of view) part is composed of large swell systems, generated by remote wind systems, which have little correlation with the local wind conditions. This means that the two resources can appear at different times and their integration in combined farms allows a more reliable, less variable and more predictable electrical power production. The reliability is improved thanks to a significant reduction of the periods of null or very low power production (which is a problem with wind farms). The variability and predictability improvements derive from the smoothing effect due to the integration of poorly correlated diversified sources.

On the other hand the combination of wind and waves off the East Coast does not appear to be an attractive solution, due to a quite limited wave energy resource, which is strongly correlated to the local wind conditions. The results here were also coloured by the choice of a wave energy device, the Pelamis, which is more suitable to the sea states typical of the West coast. But it is reasonable to expect that even the choice of a different wave energy converter, for smaller sea states, would not improve significantly the properties of variability, reliability and predictability at this location, due to the strong correlation between the two resources.

The conclusion is, then, that the potential benefits of the integration of wind and wave resources, where the climate of the location is appropriate, are too important to be neglected. This paper establishes the groundwork to allow the quantification of these benefits, particularly from a raw resource assessment point of view. With wave energy technology becoming more mature, it will then be possible to develop a more complete analysis where these benefits are integrated, together with the actual costs of the different wave and wind technologies, in a global functional, whose optimisation shall lead to a proper dimensioning and design of offshore combined farms, given the climate of a certain location.

\section{Acknowledgments}

The authors are grateful to the Irish Marine Institute for providing real sea observations. In addition, the funding provided under the IRCSET scheme is acknowledged.

\section{References}

[1] The European Parliament. Directive of the European Parliament and of the Council on the promotion of the use of energy from renewable sources amending and subsequently repealing directives 2001/77/ec and 2003/30/ec. March 2009.

[2] Eirgrid. Quarterly review of the Irish electricity system. Autumn 2008.

[3] ESB National Grid. Impact of wind power generation in Ireland on the operation of conventional plant and economic implications. February 2004.

[4] Eirgrid. Generation adequacy report 2009-2015. November 2008.

[5] Lund $\mathrm{H}$. Renewable energy strategies for sustaibnable development. Energy 2007;32:912-9.

[6] Lund H, Mathiesen BV. Energy system analysis of $100 \%$ renewable energy systems - the case of Denmark in years 2030 and 2050. Energy 2009;34. 524-31.

[7] Grubb MJ. Value of variable sources on power systems. IEE Proceedings C 1991;138(2):149-65.

[8] Freris L, Infield D. Renewable energy in power systems. John Wiley \& Sons Inc.; 2008.

[9] Lund H. Large-scale integration of optimal combinations of PV, wind and wave power into the electricity supply. Energy 2006;31:503-15.

[10] Duić N, Carvalho MG. Increasing renewable energy sources in island energy supply: case study Porto Santo. Renewable and Sustainable Energy Reviews 2004;8:383-99.

[11] Østergaard PA. Reviewing optimisation criteria for energy systems analyses of renewable energy integration. Energy 2009;34:1236-45.

[12] Kallesøe BS, Dixen FH, Hansen HF and Køhler A. Prototype test and modeling of a combined wave and wind energy conversion system. In: Proceedings of the 8th European Wave and Tidal Energy Conference, Uppsala, Sweden, 2009.

[13] De Boor C. A practical guide to splines. Springer-Verlag; 1978.

[14] McCormick ME. Ocean wave energy conversion. John Wiley \& Sons Inc.; 1981.

[15] Ochi MK. Ocean waves: the stochastic approach. Cambridge University Press; 1998.

[16] Norgaard P and Holttinen H. A multi-turbine power curve approach. In: Nordic Wind Power Conferece, 2004.

[17] Gibescu M, Brand AJ, Koing WL. Estimation of variability and predictability of large-scale wind energy in the Netherlands. Wind Energy 2009;12:241-60.

[18] Ochi MK. Applied probability and stochastic processes. Wiley Inter-Science; 1990.

[19] Hong X, Billings SA. Time series multistep-ahead predictabilityt estimation and ranking. Journal of Forecasting 1999;18:379-423.

[20] Shannon CE. The mathematical theory of communication. Bell System Technical Journal 1948;27:379-423.

[21] Costa A, Crespo A, Navarro J, Madsen H, Feitosa E. A review on the young history of the wind power short-term prediction. Renewable and Sustainable Energy Reviews 2008;12:1725-44.

[22] Kariniotakis G, Pinson P, Siebert N, Giebel G and Barthelmie R. The state of the art in short-term prediction of wind power - from an offshore perspective. In: Sea Technology Week, October 2004. 